\title{
Insurance and safety after September 11, 2001: Coming to grips with the costs and threats of terrorism
}

\author{
Robin M. Hogarth ${ }^{\dagger}$
}

October 2002

\footnotetext{
ICREA Research Professor at Universitat Pompeu Fabra, Barcelona, Spain. The author is grateful to Dwight Jaffee and Thomas Russell for conversations while preparing this chapter. The chapter is an extension of a paper published on the Social Science Research Council webpage as a response to the terrorist attacks of September 11, 2001 -- see http://www.ssrc.org/sept11/essays/hogarth.htm
} 


\begin{abstract}
This chapter, originally written as a consequence of the terrorist attacks of September 11, 2001, provides an elementary, everyday introduction to the concepts of risk and insurance. Conceptually, risk has two dimensions: a potential loss, and the chance of that loss being realized. People can, however, transfer risk to insurance companies against the payment of so-called premiums. In practice, however, one needs accurate assessments of both losses and probabilities to judge whether premiums are appropriate. For many risks, this poses little problem (e.g., life insurance); however, it is difficult to assess risks of many other kinds of events such as acts of terrorism. It is emphasized, that through evolution and learning, people are able to handle many of the common risks that they face in life. But when people lack experience (e.g., new technologies, threats of terrorism), risk can only be assessed through imagination. Not surprisingly, insurance companies demand high prices when risks are poorly understood. In particular, the cost of insurance against possible acts of terrorism soared after September 11. How should people approach risk after the events of that day? Clearly, the world needs to protect itself from the acts of terrorists and other disturbed individuals. However, it is also important to address the root causes of such antisocial movements. It is, therefore, suggested that programs addressed at combatting ignorance, prejudice, and social inequalities may be more effective premiums for reducing the risk of terrosrtism than has been recognized to date.
\end{abstract}

Keywords: decision making; risk; insurance; terrorism; September 11 JEL classification: D18, D21, D81, D82 


\title{
Insurance and safety after September 11, 2001: Coming to grips with the costs and threats of terrorism
}

\author{
Robin M. Hogarth ${ }^{\dagger}$
}

Following the devastating events of September 11, 2001 it has become commonplace to hear statements to the effect that the world has become a "riskier" place. However, what do people mean by this statement? And - if we accept that it is true - how does it affect the way that people do and should behave? The purpose of this chapter is to shed some light on these questions. However, because the questions are quite general, the impacts of beliefs about a riskier world are limited to an important dimension of the business world - the supply of and demand for insurance.

At first blush, one might imagine that, with the advanced level of today's technology, the business community would have evolved sophisticated procedures for handling issues of risk and insurance following the atrocities of September 11, 2001. This turns out not to be the case. The reason - as we shall explain below - is that although the concepts of risk and insurance are simple to understand, it is not always clear how they should be applied in practice, and particularly after the occurrence of unexpected catastrophic events. I therefore first elaborate on the concepts of risk and insurance.

\section{What is risk?}

When used in everyday speech, the word risk is typically associated with an activity that involves some chance of incurring a loss or "negative outcome." Thus, for example, driving an automobile involves risk because, as we all know, accidents can and do happen. Indeed, it is impossible to live without engaging in acts that involve some degree of risk (consider crossing a road or even eating in a restaurant). Moreover, the mere fact of being alive can be thought of as being risky in the sense that there is always some chance that we could suddenly die for a variety of reasons.

From an analytical perspective, the risk of an activity can be thought of as having two components. One is the chance or probability that the negative outcome will occur; the second is the size of the outcome. Generally speaking, the larger the probability and potential loss, the greater the "risk." Risk can therefore be increased or decreased by taking actions that affect the sizes of the loss and the probability of its occurrence. Thus, for example, you may decrease the risk in driving an automobile by wearing a seatbelt (i.e., the potential loss is smaller than if no seatbelt is worn); or you may increase the risk by driving recklessly (i.e., you increase the probability of an accident).

\footnotetext{
$\dagger$ ICREA Research Professor at Universitat Pompeu Fabra, Barcelona, Spain. The author is grateful to Dwight Jaffee and Thomas Russell for conversations while preparing this chapter.
} 
Conceptually then, it is easy to think about risk. Many of the actions we take can be thought of as gambles with possible negative outcomes. If we are lucky, we don't lose, e.g., we don't have an automobile accident or die before a certain date. To make the concept of risk operational, however, is much more difficult. From an analytical perspective, you have to "know" the probability of the loss occurring and the amount of the potential loss. How do people do this?

\section{$\underline{\text { Risk and insurance }}$}

The insurance industry exists because people are willing to pay sums of money - or incur sure losses - to avoid the chance of incurring larger losses. To illustrate, imagine that you have just bought a new computer and are concerned about the possibility of its being stolen. One option open to you is to insure your computer against theft. That is, by paying a fixed sum of money - or premium - to an insurance company, the latter undertakes to pay you a larger sum of money (e.g., sufficient to buy a new computer) in the event that your computer is stolen. In other words, instead of you facing the possible negative consequences of a gamble (i.e., the loss of your computer), you pay someone else to accept the risk in your place. However, how does the insurance company decide what premium to charge, and how do you decide whether this is reasonable?

For this system to work, the insurance company needs to know the probabilities and amounts of potential losses as well as to have a sufficient number of clients so that the sum of the premiums collected is large enough to pay for any losses that are incurred. In the case of computers, insurance companies typically have extensive data on the frequencies of theft and the amounts of past losses and can therefore price their premiums so that they are not likely to lose money. They also rely on the fact that they are selling insurance to many clients for many different types of risk so that it is unlikely that they will face exceptional losses in all areas of their activities at the same time (i.e., they adopt a portfolio approach whereby they don't place "all their eggs in the same basket.")

As to consumers (e.g., computer owners), they typically do not have access to the data used by insurance companies but typically rely on "feelings" as to how badly they want the insurance (to be discussed below). In addition, many consumers know that there is a market for insurance in computer theft and that competition between insurance companies can prevent prices from becoming "unfair." In other words, the consumer can shop around.

Some consumers of insurance, however, can be as well informed as the insurance companies and do collect data about frequencies and amounts of past losses that they can use to evaluate the premiums of insurance companies. Imagine, for example, a large corporation that has thousands of computers. In this case, the customer (the corporation) may well be able to negotiate a special premium with an insurance company or, if it thinks this is still too expensive, decide to accept the risk itself (this is sometimes known as self-insurance).

In short, the insurance market provides a mechanism for quantifying risk that is expressed by the premiums paid to insure against specific risks. However, this mechanism depends heavily on two factors: one is the availability of past data that can 
be used to assess probabilities and losses; the second is competition between insurance companies that lets customers have some confidence in the level at which premiums are priced.

Conceptually, you could arrange for an insurance contract for a wide variety of different activities and, in fact, this happens. For example, pop singers buy insurance to avoid losses that could occur if their voices were damaged; pianists insure their hands; and so on. Indeed, Lloyds of London has made a specialty out of insuring people against the occurrence of many bizarre events. However, if there are no data on which probabilities and losses can be assessed, and few or no companies interested in offering insurance, the assessment of risk is problematic. Moreover, whereas as much daily activity can - and is - covered by insurance (consider, e.g., life and medical insurance), there is much that is not. This therefore raises the more general issue of how people assess risks in life and particularly when they do not have access to statistical data.

\section{$\underline{\text { Handling risk in everyday life }}$}

It is important to realize that risk is not a new phenomenon and that dealing with risk is something that humans have done ever since they evolved as a species. From an evolutionary perspective, therefore, one should expect that we would have developed innate mechanisms for handling risk and, in fact, this is true - up to a point. The mechanism that we all possess is the emotion of fear and it is illuminating to consider how this works.

Imagine that you are walking down a city street when suddenly you hear the bark of a vicious-sounding dog just behind you. Your immediate - and automatic reaction is of one fear - and this is accompanied by an involuntary movement away from the sound of the dog. In other words, fear stimulates an action on your part that helps you remove yourself from the source of danger. In this sense, the emotion of fear - and the reaction that it provokes - is part of our natural endowment for handling risky situations. Note well, there is no attempt to assess risk from the analytical perspective described above, i.e., estimating the chances that the dog will attack you and the possible physical damage that could result from such an attack. Instead, there is just one simple emotion and reaction that removes you from a "bad" situation.

The point I am making is that we do have "automatic systems" for handling situations that we recognize as risky. Thus, it is important to investigate the origins of these systems and to recognize both their possibilities and limitations. ${ }^{1}$

Our ability to recognize dangerous situations and to react in consequence can be thought of as having two sources. One is natural in the sense that it is inherited through evolution; the other is learned. Psychologists have made extensive studies of learning and it is quite clear that many fear reactions are the result of past experiences. Thus, individuals can differ significantly in how they react to different stimuli depending on their idiosyncratic experiences. One person, for example, may be quite

\footnotetext{
${ }^{1}$ Hogarth, R. M. (2001). Educating Intuition. Chicago, IL: The University of Chicago Press.
} 
afraid when flying in an airplane because of previous bad experiences; a second may feel little or no fear. The critical point about learning is that people have either experienced a negative outome (or "loss") personally or they have been socialized by others (e.g., a parent) to associate potential losses with certain activities.

It can be safely said that our understanding of how evolution has shaped us to experience fear in the face of specific stimuli is less complete than our understanding of learning. However, our ability to acquire the response of fear is a genetically inherited mechanism. In addition, there is evidence that it takes very little exposure to acquire fear reactions to some stimuli and yet not to others. For example, it takes only one or two exposures for people to acquire a fear of snakes, spiders, and heights and yet, these same people may experience far less fear when crossing a busy intersection in a city (which for them might be objectively more dangerous). It just seems that we are better "prepared" to learn fear reactions from some kinds of stimuli than others. For example, early in the $20^{\text {th }}$ century, the pioneering learning psychologist John B. Watson demonstrated that he could teach - in a conditioning experiment - an 11month boy to become afraid of a white rat, a rabbit, and a dog when these were paired with a startling noise. However, an attempt to replicate his experimental procedure failed when conventional objects such as blocks of wood and cloth curtains were paired with the startling noise.

More recently, neuroscientific studies of the brain indicate that people process information concerning fear reactions in two distinct areas. Key to the fast, automatic reactions is the amygdala, a small, peanut-sized organ that lies deep in the back of the brain. The amygdala receives information directly from the sensory thalamus and uses this to initiate evasive action if danger is signaled. This level of processing, however, is approximate in the sense that it does not involve detailed analysis of the impending danger. It acts as a kind of reflex to a class of stimuli. The incoming information, however, will also be processed - albeit in a slower and more thorough manner - in the neo-cortex at the front of the brain and this will allow a more precise identification of the potential danger and the apropriateness of different actions. This slower processing, however, will typically take place after evasive action has already been enacted (e.g., you took evasive action automatically after hearing the dog's bark and only afterwards were you able to assess the real risk when you saw - from a safe distance - that the dog was well secured). Clearly, it is functional for the first system to act quickly even if it is mistaken on occasion. More generally, several researchers believe that our emotional decision making systems - that work without our conscious awareness - are tuned through experience to pick up "markers" or signals of potential danger and that they help us to avoid making the wrong decisions by eliminating dangerous alternatives from consideration. ${ }^{2}$

Risk and past experience. Both evolution and our learning history endow us with fear reactions that can stand us in good stead when we are confronted with potentially dangerous situations. In facing the dangers in today's world, however, both mechanisms suffer from the same disadvantage. They only provide reactions to situations that have been experienced in the past and cannot handle risks or dangers

\footnotetext{
2 See, e.g., Damasio, A. R. (1994). Descartes' error: Emotion, reason, and the human brain. New York: Avon, and Ledoux, J. (1996). The emotional brain: The mysterious underpinnings of emotional life. New York: Simon \& Schuster.
} 
that are "new." Indeed, if we rely only on our emotions (whether inherited or learned) to guide our risky decision making, we are liable to suffer many losses.

The sociologist Charles Perrow has made an interesting analysis of this situation from a larger societal perspective. In a book entitled Normal Accidents he makes the point that society typically learns to handle new technologies by responding to breakdowns or "accidents." 3 For example, regulations for fire hazrds that involve limiting the number of people who can be present in buildings at the same time were not the result of authorities planning what might happen when many people crowded into the same building. Instead, they are a result of what society learned from past accidents where people died. Similarly, the loads that bridges can take were not always forecast but calculated in light of past experiences; and traffic regulations were implemented incrementally as society gained experience with accidents. Thus, argues Perrow, if society continues to act in the same fashion, accidents will also occur when new technological advances are introduced - indeed, they are inevitable or "normal." Lacking past experience that could signal danger, it is human nature to continue to push the frontier until something happens. As a recent example, consider Concorde, the supersonic jet that flew commerically without a fatal accident for some 25 years. Note that the fact that Concorde was (or is) a safe technology was re-inforced on a daily basis for a quarter of a century. However, when an unimagined and life-causing accident did occur after this long accident-free service, the airplane had to undergo substantial modifications of its undercarriage to avoid similar accidents in the future. And yet, for the first 25 years of its service, no fatal accidents had occurred and no-one saw the need to introduce the modifications.

It should be clear that, in an increasingly technological and complex society, we cannot rely only on our emotions of fear - whether these are determined genetically or environmentally (i.e., the result of experience) - to assess risk and find means to deal with it. Instead, people's assessments of the components of risk (i.e., the chances and the amounts of potential losses) must involve their subjective perceptions of what these are likely to be in the future. In turn, such assessments must depend on imaginary as opposed to "real" experience. And indeed, many studies of risk assessment over the last 30 years have highlighted the role played by imagination. Sometimes, people fail to imagine the possibility of certain risks occurring and so fail to take protective actions (e.g., the Concorde example, given above). On other occasions, people's imagination may lead them to believe that risks are greater than more objective analysis might show. In both cases, the way in which people acquire and process the information on which their assessments are based can have important impacts on their beliefs.

In the final analysis, then, people's assessments of risk depend on both their experience with situations that are similar to those they are currently facing - and particularly their feelings towards those situations - and their imagination of what the future might hold. In the case of insurance companies dealing with everyday events such as theft and general life insurance, it is clear that they are able to quantify their experience with all the data that are available to them. But individuals who face risk - and for whom data might not be available - are obliged to use their imagination, which, as it turns out, can be affected by many factors.

\footnotetext{
${ }^{3}$ Perrow, C. (1984). Normal Accidents. New York: Basic Books.
} 
Risk and imagination. One way to characterize people's assessments of risk is to explore what affects their imagination of risky events occurring. At a rough approximation - and holding size of negative outcomes constant - the easier it is for people to imagine a risky event happening, the more likely they are to perceive it as risky. What then affects people's imaginations?

Let's start with risks that people don't imagine and which therefore do not represent risks from their point of view. There are many of these in everyday life. For example (and as noted earlier), each time you walk down a street you could have an accident. However, the possibility of accidents such as these rarely comes to the attention of a fit, able person. In a sense, these accidents fall below the threshold of imagination and thus worry. Second, there are many activities where people feel "in control" and thus do not see the risks in the same way as others might. For example, when considering their ability in driving automobiles (and thus their propensity not to have accidents), most people consider themselves to be well "above average." Similarly, many business people do not consider that they are engaged in risky decision making because, not only are they in control of what they are doing, they are also experienced. ${ }^{4}$ Finally, there are many decisions where people do not experience any immediate negative feedback from taking risky actions and thus may fail to see the link between what they do now and what happens in the future. For example, the effects of eating foods with high levels of cholesterol or smoking are delayed in time. In both cases, the activities are pleasurable and negative consequences will not be experienced until much later. In fact, even if people "know" about the negative effects of tobacco and cholesterol, neither of these has much meaning to them if the consequences occur in a distant future with which they cannot identify.

There are many ways in which events can become easier to imagine and thus be perceived as more risky. First, consider the difference between describing the risk of an event in terms of statistics or stories. For example, one can describe how certain behavior can lead to a disease by factually presenting statistics, for example, specific activities increase the chances of contracting an unpleasant disease from .001 to .002. Alternatively, you could describe - in detail - how someone contracted the disease and its consequences for the person. Moreover, when the person described is relevant to the audience, the impact of the description will be greater than the statistics. Second, the manner in which statistics are presented can have further effects. For example, in one study, experienced forensic psychologists were asked to assess the risk of allowing a patient to be discharged from a mental hospital after being provided with data about similar past cases. Data presented in different formats produced quite different results. When the rate of past recividism was presented in frequencies (i.e., 20 out of 100), 41 percent refused to discharge the patient. When it was presented in probabilistic form (i.e., a 20 percent chance), only 21 percent refused. ${ }^{5}$

A further example highlights how making the description of an event very specific can induce people to see it as much more risky. In an investigation of the effects of wording on people's intentions to buy insurance for air travel, researchers

\footnotetext{
${ }^{4}$ Shapira, Z. (1995). Risk Taking: A Managerial Perspective. New York: Russell Sage Foundation.

5 Slovic, P., Monahan, J., \& MacGregor, D. G. (2000). Violence risk assessment and risk communication: The effect of using actual cases, providing instruction, and employing probability versus frequency formats, Law and Human Behavior, 24, 271-296.
} 
found that that people were willing to pay more for a policy that would insure them against "terrorist acts" as opposed to death from "all possible causes." 6 And yet, as must be obvious to the reader, death from terrorist acts is only one of many ways that could lead to death on an airplane. However, because this scenario was made explicit, it became more salient to people thereby increasing their perception of the risk as measured by their willingness to pay an insurance premium.

Following a series of extensive investigations over more than 20 years into how people perceive the risk associated with new technologies, psychologist Paul Slovic and his colleagues have determined two important dimensions. One they call dread and the other risk of the unknown. ${ }^{7}$ The former includes feelings of fear, lack of control and apprehension about catastrophic potential. The latter refers to lack of knowledge of the risk that could be unobservable, novel, and possibly have important delayed effects. Clearly, one could argue that with good information, people might be able to understand the risks better; however, this alone would not necessarily help people overcome their fear.

A related issue is whether people's concern's about one source of risk affects their attitudes toward other sources. For example, imagine that you have been sensitized to risk in one area of your life, e.g., you are concerned about the outcome of a medical treatment. Will this affect how you view risks in other areas? The evidence suggests that it will. People's assessments of risk have been found to be affected by their general emotional state, e.g., if you are scared, you are likely to see risks as generally greater than if you are not. ${ }^{8}$ As a further example, the attacks involving anthrax were seen by the general public to signal far greater risk precisely because of their temporal proximity to September 11, 2001. However, there is now considerable doubt as to whether the same terrorist organization was responsible for both the attacks on September 11 and the letters contaminated by anthrax.

To summarize, risk involves some chance of a negative - or bad - outcome occurring. The extent of risk therefore depends on both the size of the probability of the event occurring and the size of the negative outcome. In dealing with many risks, however, people (and even insurance companies) do not have access to data that allows them to assess and calculate risks in a rational manner. They therefore rely on more tacit or intuitive ways of dealing with risk that involve feelings or emotions; in addition, imagination plays an important role. Tacit or intuitive knowledge, however, is limited by past experience and imagination may be insufficient or unrealistic. In addition, both can be affected by the context of immediate experience that may or may not be relevant to the issues at hand.

$\underline{\text { Insurance after September 11, } 2001}$

\footnotetext{
${ }^{6}$ Johnson, E. J., Hershey, J., Meszaros, J., \& Kunreuther, H. (1993). Framing, probability distortions, and insurance decisions. Journal of Risk and Uncertainty, 7, 35-51.

${ }^{7}$ Peters, E., \& Slovic, P. (1996). The role of affect and worldviews as orienting dispositions in the perception and and acceptance of nuclear power. Journal of Applied Social Psychology, 26, 1427-1453. ${ }^{8}$ Loewenstein, G. F., Weber, E. U., Hsee, C. K., \& Welch, N. (2001). Risk as feelings. Psychological Bulletin, 127 (2), 267-286.
} 
Let us now return to the aftermath of September 11 and address some specific issues. How have the terrorist attacks affected the way that we experience and assess risk? Second, how have these affected insurance markets?

To answer the first question, it should be quite clear that the terrorist attacks have not affected the way that we all experience and assess risk. However, what the unforgettable television images have undoubtedly done is to increase our awareness of the possibility of terrorist attacks and the nightmarish quality of potential outcomes. At the same time, we - the general public - have become much more knowledgeable about the way terrorist networks operate, the effects of religious fundamentalism, and the limits to which fanatics are prepared to go in order to achieve their goals. For example, although most Westerners were aware of suicide bombers, the idea of killing oneself for a religious cause is not part of our way of seeing the world. September 11 helped us understand that we have a very small worldview.

From the viewpoint of understanding risk, what September 11 highlights is the two-edged nature of knowledge. On the one hand, if we are unaware of certain possibilities - i.e., we cannot even imagine them - we clearly cannot regard these events as risky. However, if we do gain some knowledge of their possibility, our awareness leads to feelings of risk even though, from an objective viewpoint, there may be no difference in the world except for our awareness. Moreover, if this knowledge is imperfect, and we know it is imperfect, then our assessment of the risk could well be biased by a number of different, unknown factors.

At the individual level, one could argue that the fact that one person has become aware of a risk may not be of great importance. However - and this is one of the critical factors of September 11 - when many people become aware of a risk, the implications are quite different. A classic illustration can be provided by what happens in certain kinds of bank failures. If one person senses a risk that a bank will fail and so withdraws his or her funds, this would typically have little effect on the bank. However, if that person communicates that feeling to others, and they to others, soon so many people will want to withdraw their funds that they will in fact bring about the failure of the bank. Panics can sometimes be instigated by totally erroneous information. People, it should be remembered, are social animals and much of what we know - including information about what is and what is not risky - is learned through social interaction. Thus, a critical part of managing situations such as the aftermath of September 11 depends on whether people can trust what they are told by government officials, elected representatives, or the media. If we cannot believe what we are told, our general sense of risk is accentuated.

As to the insurance markets, there are a number of effects. First, the destruction of property and lives by the terrorists was huge. Moreover, it would be fair to state that all the property (or at least almost all) was insured against all kinds of calamities and many claims have also been made in terms of life insurance, medical claims, loss of earnings, the ability of firms to operate, and so on. Thus in the short term, insurance companies had to pay out huge sums of money. In fact, it has been reported that the claims submitted to Lloyds of London represented the largest single loss in its venerable 300-year history. Indeed, special facilities had to be extended to Lloyds in order for payments to be made on time. Second, despite the short-term 
difficulties of meeting the payments attributable to September 11, the immediate prospects for the insurance market were seen to be quite rosy. For example, two months after September 11, the stock price of the large German insurance group Allianz had risen $31 \%$; the price of its large French competitor, Axa, had risen $44 \%$. In other words, shortly after September 11, investors believed that insurance was a good business.

Why should investors believe that an industry that has just suffered huge losses is going to do exceptionally well in the future? The answer can be found in our previous discussion. First, the effect of September 11 was to increase people's perception of the level of general uncertainty in the world and their imagination of the kinds of negative events that could occur. This uncertainty, in turn, engendered a desire to take actions that can reduce the uncertainty. Many kinds of actions are possible. For example, one can avoid taking airplane flights and thereby reduce some obvious risks. (In fact, in October 2001, major US air carriers reported reductions of between $25 \%$ and $33 \%$ in passenger traffic.) People can also take out insurance to protect themselves from many different kinds of potential losses, e.g., destruction of homes, the need for medical treatment, and so on. They may also decide that, in light of recent events, their current insurance coverage is insufficient and that they need to protect themselves against larger potential losses. In other words, one major effect of September 11 was to increase the demand for insurance. And, when demand for a product increases, suppliers (in this case insurance companies) can be more selective with their customers and also increase prices.

However, there is another reason why insurance companies increased prices and this also relates to increased uncertainty. Simply stated, before September 11 insurance companies had never faced such a devastating loss. Moreover, this one loss makes an approach to assessing risk based on looking at past data anomalous. The past data approach works only really when you are dealing with many relatively small losses over time that occur in a manner that allows premiums to be calculated in a straightforward way (see above). However, catastrophes - like September 11 - send a signal that the world might have changed and that the kinds of losses that will occur in the future may be different from what happened in the past.

When thinking about the effects of September 11 on insurance, it is illuminating to consider three classes of events. The first are events that have nothing to do with terrorism, e.g., automobile theft. The second is insurance for events that are directly related to terrorism such as clauses that specifically provide coverage against acts of terrorism in the insurance contracts of, say, commercial airlines or large commerical properties. The third class are events that, although not directly attributable to terrorism, could be linked conceptually to possible terrorist acts. Consider, for example, general health and life insurance, claims for damage from fire or floods and other events that could be triggered by acts of terror, and so on.

Clearly, there is no reason to believe that September 11 should have any effect on the first class of events. However, it is easy to understand how the availability in imagination of the events of that day would affect the second and third class of events. In short, when dealing with potentially catastrophic events, insurance companies act in ways similar to individuals - they try to avoid risk. Thus, less than six months after September 11, a statement by Richard J. Hillman of the United States General 
Accounting Office reported to Congress that "both insurers and resinsurers have determined that terrorism is not an insurable risk at this time." 9 In his testimony, Hillman stressed that insurers were specifically withdrawing from providing insurance against terrorist attacks or, if they did so, were demanding very high prices. For example,

An owner and operator of a midwestern city's principal airport and several smaller airports reportedly experienced a 280 percent increase in its aviation liability premium for 2002. The new policy does not include war risk. The insurer offered $\$ 50$ million in war risk and terrorism coverage back to the airport owner in a stand-alone policy for a premium of $\$ 1$ million. The owner needs $\$ 500$ million in coverage to satisfy its obligation to customers. ${ }^{10}$

Similarly, Hillman reported cases where the owners of large buildings in cities were unable to obtain insurance coverage against possible acts of terrorism. In effect, many major buildings now no longer have insurance against terrorist acts or have less than adequate coverage - often with the implicit agreement of mortgage holders and other financial stakeholders who previously required insurance against possible terrorist acts.

It is clear that the terrorist attacks of September 11, 2001 have greatly affected the market for certain kinds of insurance in the United States as well as the general business climate. As noted above, given a general sense of insecurity in the world, people may well be interested in demanding insurance against a wider range of risks and insurance companies will be tempted to raise prices (possibly also hoping to offset losses induced by September 11 - related events). However, what is not clear at the present time is whether the current perception of risk will prevail or, on the other hand, simply have a transitory effect. One way of thinking about this is to see how insurance markets have reacted to other catastrophes in the past. Consider, for example, the experience in California following the 1994 Northridge earthquake. Here, the vast majority of insurers involved in providing earthquake insurance on homeowners policies either stopped providing insurance or imposed strict limits on their policies. ${ }^{11}$

At one level, the similarity of these reactions is easy to understand. The occurrence of a catastrophic event is costly and the fact that it has occurred suggests that it could happen again. In addition, whereas it simple to think about the theory of insurance by making an analogy to gambling, there is a substantial psychological difference between gambling in a game such as, say, roulette where the probabilities of losses and gains can be calculated precisely and events such as terrorist attacks and earthquakes where the appropriate probabilties are not evident. Our beliefs about the probabilities of future earthquakes or terrorist attacks are clearly going to be affected by what happens in the short and medium term. If there are no major terrorist attacks

\footnotetext{
${ }^{9}$ Hillman, Richard J., (2002). Terrorism insurance: Rising uninsured exposure to attacks heightens potential economic vulnerabilities. Testimony before the Subcommittee on Oversight and Investigations, Committee on Financial Services, House of Representatives (February 27). GAO-02$472 \mathrm{~T}$.

${ }^{10}$ Hillman, ibid, p. 11.

${ }^{11}$ Jaffee, D. W., \& Russell, T. (1997). Catastrophe insurance, capital markets, and uninsurable risks. The Journal of Risk and Insurance, 64(2), 205-230.
} 
in the next few years, then it is probable that people's perceptions of the risk could diminish. On the other hand, another major attack could convince people that the risks are even greater. As indicated above, this is one reason why the anthrax attacks had such an impact in the fall of 2001.

There is clearly a need for insurance against terrorist attacks and other potentially catastrophic events. Moreover, in the developed world, markets typically arise to meet such needs. Why then, is the market for catastrophic insurance such an exception and what, if anything, can or should be done about this? The fundamental reason probably lies in the fact that, in order to face potential catastrophic risks, insurance companies need to maintain large amounts of liquid capital. However, according to Dwight Jaffee and Thomas Russell ${ }^{12}$, this is not facilitated in the US by institutional factors that involve, inter alia, accounting regulations, tax laws, and the threat of takeover of companies with large cash reserves. Indeed, Jaffee and Russell state that the failure of the insurance market to provide coverage against catastrophic events is due to idiosyncracies or failures in the capital markets as opposed to problems with insurance per se. On the other hand, Howard Kunreuther has pointed out that even if potential investors are offered the chance to buy what seem like quite profitable catastrophe bonds (i.e., so-called "cat bonds"), there is considerable reluctance to do so. ${ }^{13}$ In other words, there is considerable aversion to investing in companies or financial instruments that depend on events that are characterized by large potential losses and unknown probabilities (however small the reasonable upper bounds of these probabilities might be).

In fact, many countries in the Western world now have policies whereby governments have effectively agreed to become the insurers of last resort in the case of catastrophes. This is the case, for example, in Great Britain, France and Israel although what differs between countries is the methods governments use to build up necessary funds across time, e.g., by imposing a levy on all private insurance contracts (France), a "pool" or risk-sharing appoach (UK), or specific taxes on property (Israel). As can be seen, however, the final costs of insuring against catastrophes is borne by the citizens of each country; what varies is how such costs are borne by different segments of the population. Currently (September 2002), it is this issue that is being debated in the US.

Finally, we referred above to the fact that the share prices of insurance companies rebounded quickly in the aftermath of September 11, 2001. Subsequently (through September 2002), share prices have dropped considerably along with the share prices of almost all sectors of business activity. However, it would be foolish to attribute this drop in prices on the events of September 11, 2001. Instead, it is much more indicative of the general malaise in share prices that has swept over the world economy in the last year.

\footnotetext{
12 Jaffee \& Russell, ibid.

${ }^{13}$ Kunreuther, H. (2002). The role of insurance in managing extreme events: Implications for terrorism coverage. Risk Analysis, 22(3), 427-438.
} 
Should we change what we do?

It is clear that the events of September 11, 2001 have had important effects on insurance markets. But, has the world really become a more risky place in which to live and should we change our behavior in consequence? In addition, how can the concepts of risk and insurance help us deal with the threats posed by terrorism?

As noted above, one effect of September 11 has been to increase our general awareness of risk. However, if it were possible to establish an objective measure of risk, an argument could be made that the world has become a less risky environment. The reason is that since September 11 society has started taking actions that reduce risk. For example, security at airports - although far from perfect - has been increased; emergency planning and procedures have been established in many public locations; there is a heightened state of surveillance in many public services; and so on. Paradoxically, the mere existence of these measures can accentuate the perception of risks of which we were previously unaware thereby making the world seem more risky. On the other hand, this assessment could be quite wrong in the sense that none of these measures are sufficient to overcome the increased risks that terrorist groups are willing to impose on society. In other words, assessing the "real" level of risk is quite complex because it depends on the actions taken by many different parties.

We can also ask whether the world is a more risky environment than it was, say, 100 years ago. When we think of all the dangers of modern technology, most people's immediate reaction is to say that it is more risky or dangerous. Certainly, it is easier now to imagine ways in which the planet can be put at peril and by which we could all die. Indeed, hardly a day passes without the media reporting on disasters that occur in different parts of the world - whether induced by natural causes (e.g., earthquakes, floods) or human actions (e.g., wars, technological failures, and so on). Humans possess the means to impose massive destruction and we cannot necessarily control who has and does not have access to such technology. On the other hand, it is also true that life expectancy has increased dramatically over the last century and, on this basis alone, one could argue that the world has become a lot safer. What has changed is the nature of the risks that we now face. For example, whereas we have learned to reduce many risks faced by our ancestors such as those induced by lack of appropriate sanitation in urban areas (that killed millions), our civilization has invented new hazards with catastrophic potential.

Above we alluded to the similarity between risks from terrorism and risks from earthquakes. Both can occur at unpredictable moments and have catastrophic consequences. However, there is a critical difference between the two. Earthquakes are a natural occurrence; acts of terrorism are not. This means, therefore, that whereas - as humans - we have to accept the inevitability of earthquakes, this is not necessarily the case with terrorism although we do need to be realistic.

In addition to the events of September 11, recent years have shown that individuals or small groups can have access to materials that can be used for terrorist acts. Consider, for example, the IRA in the United Kingdom, the ETA group in Spain, the Oklahoma bombing in the United States, the Kashmire dispute, suicide bombers in the Middle East, and so on. In addition, disturbed individuals who engage 
in deadly shooting rampages should also be thought of as terrorists. One lesson society should have learned from recent years is that despite all the safeguards that have been implemented against potential terrorist acts, deranged individuals are capable of creating new methods of terrorism of which we are not yet aware. In short, although acts of terrorism are not inevitable at a conceptual level, the world needs to act as though they are.

This therefore raises the issue of how the concepts of risk and insurance can be used as tools to enable society to deal with terrorism. As noted at the outset of this chapter, one of the defining dimensions of risk is the probability of negative consequences occurring. And indeed, society recognizes this. Consider, for example, all the safety measures that have been installed at airports and public buildings to reduce the chances that people can carry out acts of terror. Consider too the actions taken by the United States and its allies to eliminate the Al Qaeda terrorist group and similar organizations around the world. All these measures, however, are limited in the sense that they accept the status quo of terrorist groups and do not necessarily reach the root causes of many acts of terrorism. Why, we should ask, do so many people want to join terrorist groups and engage in such horrendous acts? Although the reasons are undoubtedly complex, I strongly suspect that the root causes involve prejudice, ignorance, and a hopeless sense of inequality. Indeed, I fear that the probability of continued terrorist acts will remain high until these ills are mitigated and this therefore raises the issue of what the world community is actually doing about them.

In dealing with potential acts of terrorism, insurance per se can be no more than a palliative. However, at a conceptual level, we can ask the question of what premium we would be prepared to pay reduce the level of terrorism that is engendered by the potential root causes mentioned above. For example, as a society we are willing to spend billions of dollars in safety measures and military campaigns to contain potential acts of terrorism that we can identify. Why then are we not willing to spend similar sums on programs that will foster health and education and help to eliminate prejudices? As noted above, there is a kind of precedent. In the late $19^{\text {th }}$ century, the western world started insuring against many diseases by installing sanitation facilities in urban areas. The effect was so dramatic that now we all take this "health coverage" for granted. In similar fashion, massive investment in education in developing countries may be the "best" premium we can pay to reduce the risks of potential terrorist activity in the future. 